\title{
Detection of Soilborne Alternaria radicina and Its Occurrence in California Carrot Fields
}

\author{
B. M. Pryor, R. M. Davis, and R. L. Gilbertson, Department of Plant Pathology, University of California, Davis \\ 95616
}

\begin{abstract}
Pryor, B. M., Davis, R. M., and Gilbertson, R. L. 1998. Detection of soilborne Alternaria radicina and its occurrence in California carrot fields. Plant Dis. 82:891-895.

Alternaria radicina, causal agent of black rot disease of carrot, was recovered from soil by plating dilutions on a semi-selective medium, A. radicina semi-selective agar. The efficiency of this soil assay was $93 \%$ based on recovery of the fungus from non-infested field soil amended with $A$. radicina conidia. Soilborne A. radicina was recovered from five of six carrot-growing areas in California, but was only commonly found in the Cuyama Valley, where the fungus was detected in $83 \%$ of sampled fields. Over a 3 -year period of sampling, A. radicina soil populations in Cuyama Valley fields prior to carrot planting ranged from 0 to $317 \mathrm{CFU} / \mathrm{g}$. There was a positive correlation between $A$. radicina soil populations in these fields and the incidence of black rot disease at harvest. A. radicina was recovered from dry soil after 4 years of storage, and the fungus survived in this soil as solitary conidia or as conidia associated with organic debris.
\end{abstract}

Black rot of carrot, caused by the fungus Alternaria radicina, occurs in most carrotgrowing regions of the world $(5,14,17)$. The disease is characterized by black necrotic lesions on carrot leaf petioles, crowns, and tap roots. In severe infections, foliage and roots may completely decay. Typically, the fungus infects the bases of petioles, resulting in a black ring of decay around the top of the tap root that reduces carrot quality (Fig. 1). Extensive petiole infection also results in excessive breakage of weakened, rotten petioles during mechanical harvesting, which may lead to significant crop loss. In addition, the fungus can cause seedling damping off, postharvest losses, and poor seed quality $(7,11,12,14,16-18,21)$.

In California, over 29,000 ha of carrots are grown in four major areas (1; Fig. 2). Black rot is generally not a problem except in the Cuyama Valley, an isolated semi-arid valley that contains approximately $10 \%$ of the state's carrot acreage (Fig. 2). Here, black rot is common and can be found, to some extent, in almost every carrot field. Application of fungicides to control the

Corresponding author: B. M. Pryor

E-mail: bmpryor@ucdavis.edu

This work was partially supported by the California Fresh Carrot Advisory Board, the StorkanHanes Research Foundation, and the College of Agricultural and Environmental Sciences, University of California, Davis.

Accepted for publication 24 April 1998.

Publication no. D-1998-0615-06R

(C) 1998 The American Phytopathological Society disease generally has been unsuccessful due, in part, to the difficulty in targeting fungicides to the mature carrot crown once the crop canopy has closed. Growers attempt to use 3-year crop rotation schedules in most fields for disease management, but production demands frequently result in shorter rotations.

The introduction of $A$. radicina into carrot production areas is generally attributed $(17,18,20,21)$. Once introduced into an area, the fungus can persist in the soil for long periods and cause disease in subsequent carrot crops (11-13). Although the occurrence of soilborne disease inoculum has been previously documented, little quantitative data is available on $A$. radicina soil population density, its persistence in soil, or the relationship between soil populations and the incidence of carrot black rot disease.

In a previous study, commercial carrot seed lots used in the Cuyama Valley were assayed for $A$. radicina infestation with a selective medium, $A$. radicina semi-selective agar (ARSA; 19). Because A. radicina was only detected at low levels in a small percentage of the seed lots tested, it was suggested that soilborne rather than seedborne inoculum was responsible for the unusually high incidence of black rot in this area.

The objectives of this work were to develop a method for the detection and enumeration of soilborne $A$. radicina, to determine the occurrence of soilborne $A$. radicina in California carrot production areas, to determine the relationship between soil populations of the pathogen and the incidence of black rot in the Cuyama to planting infested carrot seed
Valley, and to identify fungal structures associated with its long-term survival in soil.

\section{MATERIALS AND METHODS}

Assay for soilborne A. radicina. A. radicina was recovered from soil by plating aliquots of soil dilutions onto ARSA. Samples of soil were air-dried in paper bags at ambient laboratory temperature (approximately $22^{\circ} \mathrm{C}$ ) for 1 week, crushed in a mechanical soil grinder (Braun Corporation, Los Angeles), and passed through a \#20 US standard sieve. This processed soil $(4 \mathrm{~g})$ was added to $40 \mathrm{ml} 0.2 \%$ water agar in a milk dilution bottle (1:10 dilution), and the bottle was shaken vigorously for 20 to $30 \mathrm{sec}$. This soil suspension $(1 \mathrm{ml})$ was pipetted onto the surface of each of three plates of ARSA without 2,4-D (19) and spread evenly over the surface of the agar using a petri plate turntable and a bent glass rod. Plates were incubated for 14 days at $28^{\circ} \mathrm{C}$ in darkness. The undersurface of each plate was examined with a dissecting microscope $(7 \times$ to $30 x)$ for characteristic $A$. radicina colonies growing into

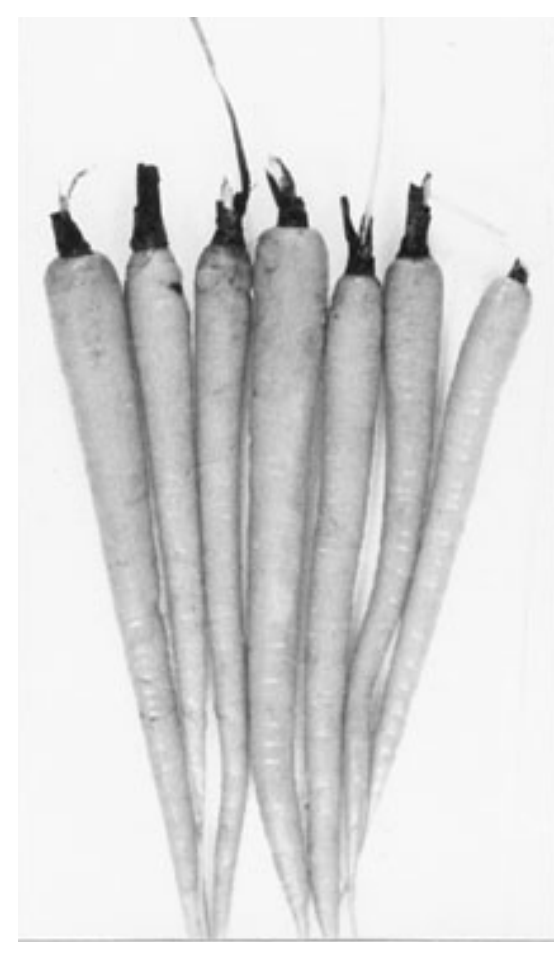

Fig. 1. Carrots with typical black rot symptoms. 
the agar medium (19). Values for the three plates were averaged to obtain CFU/g soil for each sample.

The efficiency of recovery of this soil assay was evaluated based upon recovery of known quantities of $A$. radicina conidia amended into non-infested native soil collected from the Cuyama Valley. A suspension of conidia was prepared by flooding a 21-day-old culture on potato dextrose agar (PDA) with sterile $\mathrm{H}_{2} \mathrm{O}$ and gently dislodging conidia with a plastic rod. The suspension was filtered through three layers of cheese cloth and the concentration of conidia was determined with a hemacytometer. The suspension was adjusted with sterile $\mathrm{H}_{2} \mathrm{O}$ to a concentration of 2,000 conidia/ $\mathrm{ml} \mathrm{H}_{2} \mathrm{O}$, and serial dilutions (1:10, $1: 100$, and $1: 1,000)$ were plated on ARSA to confirm the number of viable conidia in the adjusted suspension. To infest soil, 100 $\mathrm{ml}$ of this suspension was slowly added with a pipette to $1 \mathrm{~kg}$ soil that was tumbling in a rotating cylinder. The infested soil was processed and A. radicina soil population densities were determined as previously described. Three separate assays were performed with each infested soil sample and the results were averaged. This experiment was conducted three times.

Survey of soil from California carrot production areas. In 1993 to 1995, soil samples were collected from carrot production fields in the four major carrot-production areas of California: Kern County, the Cuyama Valley, the Salinas Valley, and the Imperial Valley (Fig. 2). In 1995, samples also were collected from fields in two desert valleys located in the eastern part of the state, Owens Valley and Fish Lake Valley. Most fields had produced carrot crops within the previous 2 years, and were fallow and relatively dry at the time of

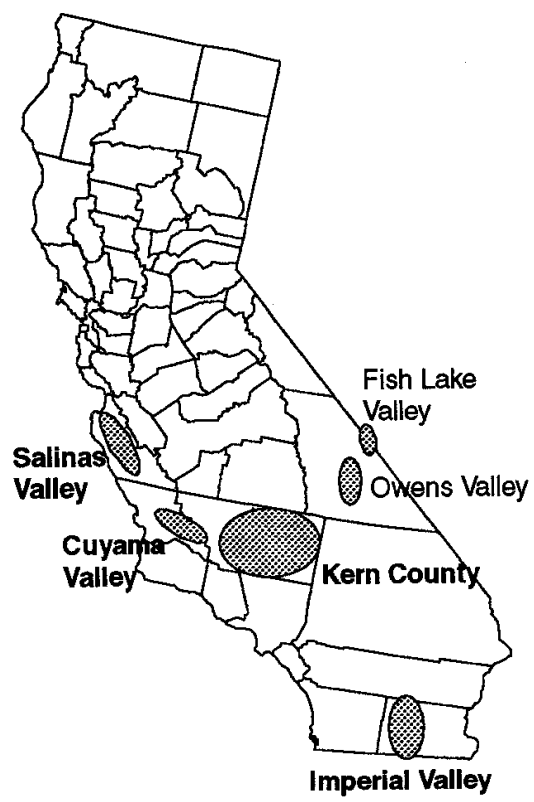

Fig. 2. Major (bold) and minor carrot production regions in California. sampling. In 1993, two of the fields sampled in the Cuyama Valley were new production fields that had been recently cleared of native vegetation. Soil samples also were collected from eight locations in the Cuyama Valley that had undisturbed native vegetation (e.g., desert scrub and grasses).

Soil samples were collected from a 4-ha site delineated within each field or native area. Ten $2.5-\mathrm{cm}$-diameter soil cores from the soil surface to $25 \mathrm{~cm}$ deep were randomly collected in a zigzag pattern across each site and combined into a single sample. A second set of 10 cores was collected in the same manner and combined into a second sample. Each sample was assayed for A. radicina as previously described, and the values for the two samples from each site were averaged to generate the $A$. radicina soil population density. The sampling protocol was based, in part, upon the equation $n \cong 4(\mathrm{CV} \%)^{2} /(u \%)^{2}$, where $n$ is the number of individual soil cores necessary to estimate the population density with a confidence of $95 \%$, CV\% equals the coefficient of variation in population density among individual soil cores (the CV\%, which was determined from preliminary sampling of three $A$. radicina-infested fields, was $32.1 \%[n=3, s=4.2]$ ), and $u \%$ is the amount of variation from the true mean acceptable to the experimenter (set at $20 \%$; 6).

Relationship of soil inoculum to disease. In 1993 to 1995,25 fields in the Cuyama Valley were selected to study the relationship between soil populations of $A$. radicina and the incidence and severity of black rot. Soil types ranged from loamy

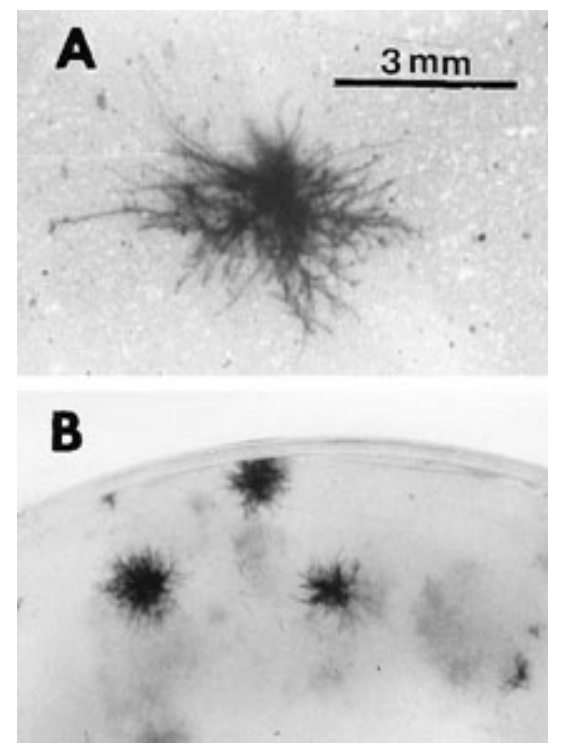

Fig. 3. Distinctive growth and appearance of Alternaria radicina on A. radicina semi-selective agar (ARSA) after recovery from soil. (A) Single colony showing characteristic growth of black hyphae. (B) Soil dilutions plated on ARSA showing distinctive A radicina colonies compared with those of other soil fungi. sand to loam. All fields were managed by a single grower and were planted between mid-March and mid-June. Similar cultural practices were used in all fields with the exception of carrot variety. All fields were irrigated by overhead sprinklers and were harvested 15 to 19 weeks after planting.

Fields were relatively dry and had most pre-plant ground preparations completed at the time of sampling. Soil samples were collected from a 4-ha site delineated within each field, and average $A$. radicina soil population densities were determined for each site as previously described. Soil population data were transformed $(\log [n+$ 1]) for regression analysis.

Approximately 1 week prior to harvest, carrots from each site were evaluated for black rot incidence and severity. At each site, all carrots in 10 randomly selected $0.5-\mathrm{m}$ sections of bed were lifted and rated for black rot symptoms using a disease rating system in which $0=$ no symptoms; 1 = black lesions on one to several petioles; $2=$ black necrosis of all outer petioles creating a black ring of decay at the carrot crown; 3 = black necrosis of all petioles or black necrosis extending $<8 \mathrm{~mm}$ from the crown into root tissue; and $4=$ black necrosis extending into carrot tissue $>8 \mathrm{~mm}$ from the crown. Average disease incidence (percent carrots with black rot) and a mean black rot rating were determined for each site. The relationship between soil population densities and the incidence of black rot was determined for each year and for combined years by linear regression analysis.

Long-term survival of $A$. radicina in soil. In March 1992, $0.5 \mathrm{~kg}$ soil was collected from each of $10 \mathrm{~A}$. radicina-infested carrot fields in the Cuyama Valley and stored in paper bags at ambient laboratory temperature and humidity. Shortly after sampling, these soil samples were assayed for soilborne $A$. radicina as previously described. Soil population densities ranged from 25 to 205 CFU/g soil. In May 1996, after 4 years of storage, these soil samples were assayed again for $A$. radicina. The results of the two assays were compared to assess long-term survival of $A$. radicina in soil.

To determine the form in which $A$. radicina was surviving in these samples after the 4-year storage period, soil from each of three different samples was diluted (1:100) in $0.2 \%$ water agar, and 1-ml aliquots were spread onto 10 plates of ARSA for each sample. This dilution allowed for observation of initial hyphal growth from $A$. radicina survival structures without the interference of soil particles or the growth of other fungi. Plates were incubated for 14 days at $28^{\circ} \mathrm{C}$ in darkness, and were examined on day 3 for initial fungal growth using a dissecting microscope at $30 \times$ and a compound microscope at $100 \times$. The structures from which hyphal growth emerged were noted and marked. After 14 days, colonies that developed from the germina- 
tion of these structures were either directly identified as A. radicina based upon characteristic growth on ARSA, or subcultured on acidified PDA for identification.

\section{RESULTS}

Recovery of $A$. radicina from soil. The growth of bacteria and most common soilborne fungi, such as Cladosporium, Fusarium, Penicillium, and Rhizopus spp., was inhibited on ARSA. The vegetative growth of $A$. radicina on ARSA was distinctive from growth of the few other fungi that grew on ARSA, such as A. alternata, Ulocladium spp., and Stemphylium spp. A. radicina produced characteristic black hyphae that grew downward into the medium with little aerial growth (Fig. 3A). Hyphal branching initially was sparse and irregular, but became more dense as the colonies grew. The hyphae of other fungi generally were lighter in color with denser branching patterns. The production of conidia on ARSA by all fungi, including $A$. radicina, was irregular and was not used as the basis for identification. After 14 days of incubation, $A$. radicina colonies ranged from 2 to $10 \mathrm{~mm}$ in diameter. Large colonies ( 5 to $10 \mathrm{~mm}$ in diameter) could be visually identified without magnification (Fig. 3B), whereas smaller colonies $(<5$ $\mathrm{mm}$ in diameter) required magnification ( $7 \times$ to $30 x)$ for identification. Quantification of $A$. radicina in soil dilutions less than 1:10 was not possible because it was difficult to identify colonies due to soil matter on the agar surface.

The concentrations of viable conidia in the spore suspensions used to infest the soil samples for the three experiments conducted to establish the efficiency of recovery were $2,030,2,200$, and 1,880 conidia/ml, respectively. $A$. radicina soil population densities recovered from the three amended soil samples were 221, 181, and $165 \mathrm{CFU} / \mathrm{g}$ soil $(n=3, s=37.3,43.3$, and 17.8 , respectively). Based upon these results, an average of $93 \%(n=3, s=14.2)$ of the amended conidia were recovered from each soil sample.

Soil survey. A. radicina was frequently recovered from carrot fields in the Cuyama Valley, whereas it was infrequently recovered from fields in the other carrot-growing areas (Table 1). In the Cuyama Valley, A. radicina was recovered from $87 \%$ of fields in which carrots had been previously produced, and soil population densities ranged from 0 to $317 \mathrm{CFU} / \mathrm{g}$ soil. For fields in which the population density was greater than $20 \mathrm{CFU} / \mathrm{g}$ soil, the $\mathrm{CV} \%$ between duplicate soil samples averaged $18.4 \%$ ( $n=11, s=12.6$ ). The fungus was not recovered from Cuyama Valley fields that had no history of carrot production, nor from any of the sites having native vegetation. In the Salinas Valley, $A$. radicina was recovered from 2 of 20 fields, and the soil population densities were 93 and $53 \mathrm{CFU} / \mathrm{g}$ soil. A. radicina was recov- ered from 2 of 40 fields in Kern County, and from 2 of 10 fields in the eastern desert valleys. Soil population densities in these four fields were $<5 \mathrm{CFU} / \mathrm{g}$ soil. A. radicina was not recovered from any of the 20 fields sampled in the Imperial Valley.

Relationship of soil inoculum to disease. A. radicina population densities in fields selected to evaluate the relationship between levels of soil inoculum and black rot incidence ranged from $0 \mathrm{CFU} / \mathrm{g}$ (in the two fields that had no history of carrot production) to $187 \mathrm{CFU} / \mathrm{g}$ soil. For fields in which the population density was greater than $20 \mathrm{CFU} / \mathrm{g}$ soil, the CV\% between duplicate soil samples averaged $11.2 \%$ ( $n=10, s=8.6)$. The incidence of black rot in these fields ranged from 4 to $91 \%$, and the average disease rating ranged from 0.06 to 1.69 . There was a significant positive correlation $(P \leq 0.05)$ between soil inoculum levels and the incidence of black rot in 1993, 1994, and $1995(y=33.26 x+$ 19.66, $r^{2}=0.92 ; y=31.79 x-12.77, r^{2}=$ 0.68 ; and $y=46.04 x-27.24, r^{2}=0.82$; respectively). Although the incidence of disease was significantly higher $(P \leq 0.05)$ in 1993 than in 1994 and 1995, the relationship between soil inoculum level and disease incidence (slope) was not significantly different $(P \leq 0.05)$ among these years. Moreover, analysis of combined data for these years revealed a significant positive correlation $(P \leq 0.05)$ between $A$. radicina soil populations at the time of planting and the incidence of black rot at harvest (Fig. 4), and a significant positive correlation $(P \leq 0.05)$ between the incidence of disease and black rot rating ( $y=$ $\left.1.75 x-0.059, r^{2}=0.96\right)$.

Survival in soil. $A$. radicina population densities decreased an average of $54 \%(n=$ $10, s=27.0$ ) in the $10 \mathrm{~A}$. radicina-infested soil samples that were stored for 4 years at ambient laboratory temperature and humidity. In experiments to determine the survival structure or structures for $A$. radicina in soil, all putative $A$. radicina colonies that grew from soil dilutions plated on ARSA originated from dark, multi-celled conidia that were either free in the soil or were associated with small pieces of debris. No other fungal structures, such as microsclerotia or chlamydospores, were associated with the development of these colonies. After 14 days of incubation, approximately $50 \%$ of these colonies were positively identified as $A$. radicina based upon characteristic growth on ARSA, whereas the other colonies were identified as Ulocladium spp. or other Alternaria spp.

\section{DISCUSSION}

The semi-selective medium for $A$. radicina, ARSA, has been used to assay commercial carrot seed lots for A. radicina infestation. Here, we report that ARSA also can be used for detection and enumeration of the fungus from soil. The efficient quantification of soilborne plant pathogens can be an important tool in the long-term management of several diseases $(2,4,8,10,15,23)$. ARSA allows for the

Table 1. Survey of soilborne Alternaria radicina in California carrot-production regions, 1993 to 1995

\begin{tabular}{|c|c|c|c|}
\hline \multirow[b]{2}{*}{ Year, region } & \multirow[b]{2}{*}{ Fields with $A$. radicina/total ${ }^{b}$} & \multicolumn{2}{|c|}{ Soil population density (CFU/g) } \\
\hline & & Average & Range \\
\hline \multicolumn{4}{|l|}{$\overline{1993}$} \\
\hline \multicolumn{4}{|l|}{ Cuyama Valley } \\
\hline Carrot fields ${ }^{\mathrm{c}}$ & $18 / 20$ & 52.9 & $0-316.6$ \\
\hline New carrot fields ${ }^{\mathrm{d}}$ & $0 / 2$ & 0 & $\ldots$ \\
\hline Native areas $^{\mathrm{e}}$ & $0 / 4$ & 0 & $\ldots$ \\
\hline Kern County & $0 / 10$ & 0 & $\ldots$ \\
\hline Salinas Valley & $2 / 10$ & 14.7 & $0-93.3$ \\
\hline \multicolumn{4}{|l|}{1994} \\
\hline Cuyama Valley & $14 / 16$ & 10.4 & $0-58.3$ \\
\hline Kern County & $1 / 10$ & 0.5 & $0-5.0$ \\
\hline Salinas Valley & $0 / 10$ & 0 & $\ldots$ \\
\hline \multicolumn{4}{|l|}{1995} \\
\hline \multicolumn{4}{|l|}{ Cuyama Valley } \\
\hline Carrot fields & $3 / 4$ & 8.4 & $0-23.3$ \\
\hline Native areas & $0 / 4$ & 0 & $\ldots$ \\
\hline Kern County & $1 / 20$ & 0.25 & $0-5.0$ \\
\hline Imperial Valley & $0 / 20$ & 0 & $\ldots$ \\
\hline Owens Valley & $1 / 5$ & 1.0 & $0-5.0$ \\
\hline Fish Lake Valley & $1 / 5$ & 0.7 & $0-3.3$ \\
\hline
\end{tabular}

${ }^{a}$ Samples were assayed for A. radicina by soil dilution plating on $A$. radicina semi-selective agar. Numbers represent mean soil population densities for the two soil samples per site.

${ }^{\mathrm{b}}$ Number of fields with A. radicina/number of fields sampled. A 4-ha site was delineated in each field or native area for sampling. Within each site, 102.5 -cm-diameter soil cores from the surface to a depth of $25 \mathrm{~cm}$ were randomly collected and combined into one sample. Two such samples were collected per site. All fields, unless otherwise noted, had carrot production within the previous 2 years.

${ }^{\mathrm{c}}$ Fields having had carrot production within the previous 2 years.

d Fields recently cleared of native vegetation but not yet having carrot production.

e Native areas not disturbed by agriculture; vegetation included desert scrub and grasses. 
quantification of soilborne $A$. radicina by selectively suppressing the growth of most soil organisms, thereby permitting identification and enumeration of the fungus based upon its characteristic growth and color.

The consistent recovery of $A$. radicina from Cuyama Valley fields having carrot production but not from undisturbed native soils or new production fields suggests that the establishment of this fungus in Cuyama Valley soils is associated with carrot production, and is consistent with the prevalence of black rot in this area. Moreover, the failure to detect $A$. radicina in undisturbed native soil in the Cuyama Valley suggests that the pathogen was introduced into the area, most likely in association with carrot seed. The infrequent detection of $A$. radicina from carrot fields in Kern, Imperial, and Monterey counties, which are carrot production areas that have low incidences of black rot, lends further support to the hypothesis that the high incidence of black rot in the Cuyama Valley is due to the prevalence of soilborne $A$. radicina.

The positive correlation found between soil population densities of $A$. radicina and the incidence of black rot at harvest establishes the importance of soilborne inoculum in black rot disease development in the Cuyama Valley. The greater incidence and severity of black rot disease in 1993 compared with 1994 and 1995 indicates that additional factors (e.g., environmental conditions) influence disease development. The low incidence of black rot in two fields in which soilborne $A$. radicina was not detected suggests that our soil assay may not detect low levels of inoculum that can give rise to disease. However, our results suggest that determining $A$. radicina population densities in soil could be used to predict the potential for black rot development in fields being considered for carrot production.

The low number of carrot fields having soilborne $A$. radicina in carrot-producing areas other than the Cuyama Valley is puzzling because many carrot production practices are similar throughout California. One factor that may contribute to the prevalence of soilborne A. radicina in the Cuyama Valley is crop rotation. Because of reduced water availability in the Cuyama Valley compared with other carrot-production areas, there are limited crop rotation options in many fields. Therefore, fallow rotation is commonly used between carrot crops and, combined with the semi-arid climate of the Cuyama Valley, this results in fields remaining dry for much of the year. Dry conditions can be favorable for survival of fungal propagules (22), and may favor the survival of $A$. radicina. This is supported by the fact that the highest population densities of $A$. radicina in the Cuyama Valley (>100 CFU/g soil) were recovered in fields having only fallow rotations between carrot crops.

Additional evidence for the effect of crop rotation on soil populations of $A$. radicina comes from the decline in $A$. radicina soil population densities detected in fields rotated to wheat after carrot production. In five fields that were sampled in 1993 after carrot production, then re-sampled in 1994 and 1995 following wheat crops, A. radicina soil populations decreased by an average of 37 and $79 \%$, re-

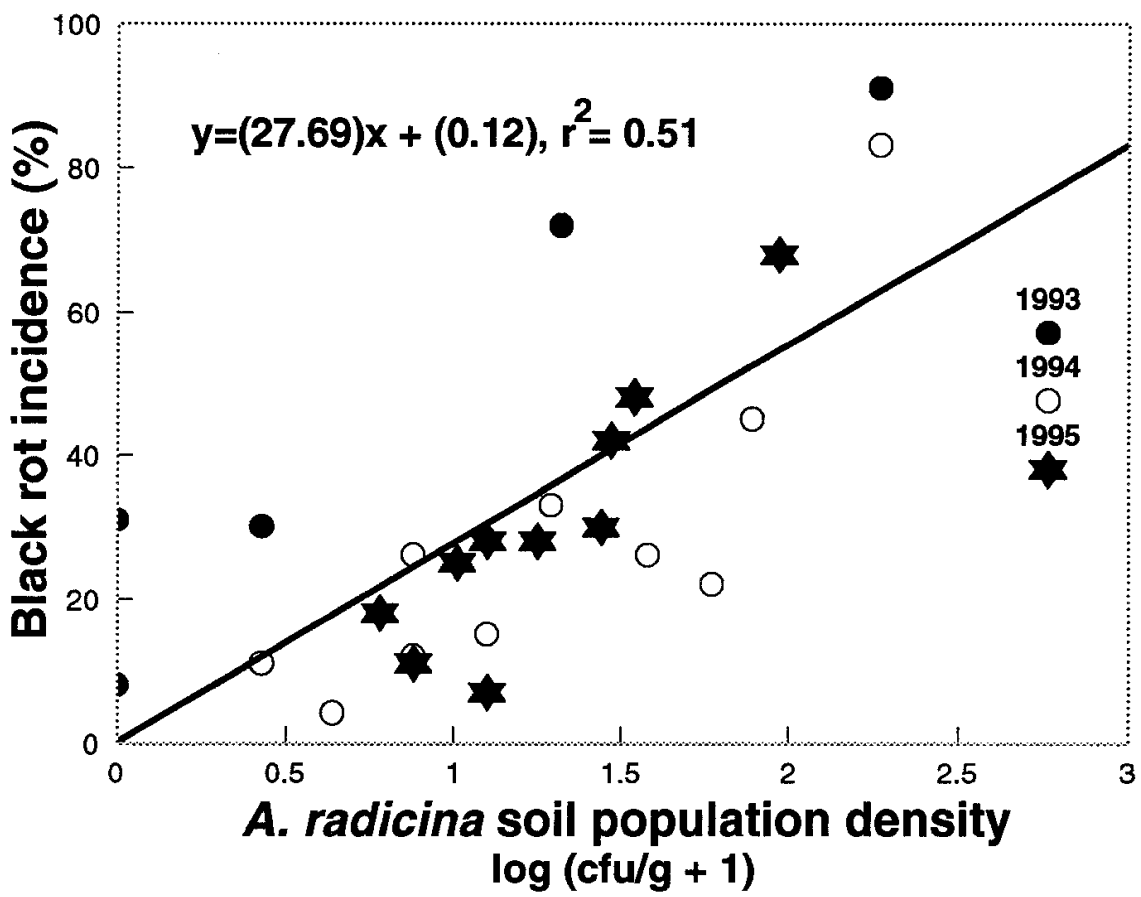

Fig. 4. Relationship between Alternaria radicina soil population density at planting and incidence of black rot disease at harvest in carrot-production fields in the Cuyama Valley. Each point represents a single field. Data for 1993 to 1995 were combined for the regression analysis. spectively (unpublished data). Future studies will attempt to identify crop rotation strategies that maximize the reduction of soilborne inoculum.

The ability to detect $A$. radicina in soil allows for the examination of its long-term survival potential in soil. We found that $A$. radicina could survive in dry soil after 4 years of storage. This is consistent with a previous study demonstrating that $A$. radicina could survive in soil for 8 years in the absence of carrot cultivation (13). Our results also reveal that $A$. radicina survives in dry soil as conidia, which have been reported to be survival structures in soil for other Alternaria spp., such as A. alternata and $A$. japonica $(3,9)$. Although there have been reports that Alternaria spp., including $A$. radicina, can produce microsclerotia $(20,24)$, no such structures were observed in our study.

The use of ARSA for the detection of $A$. radicina in soil provides a useful tool with which to investigate the etiology and epidemiology of black rot in California carrot fields. Future work will attempt to more precisely identify environmental factors and cultural practices that favor build-up and establishment of soilborne $A$. radicina in certain growing regions, such as the Cuyama Valley.

\section{LITERATURE CITED}

1. Agricultural Statistics 1997. Nat. Agric. Stat. Serv.

2. Ashworth, L. J., Bassett, D. M., Harper, D. M., and Huisman, O. C. 1979. Verticillium wilt disease of cotton: Influence of inoculum density in the field. Phytopathology 69:483489.

3. Atkinson, R. G. 1953. Survival and pathogenicity of Alternaria raphani after five years in dried soil culture. Can. J. Bot. 31:542-547.

4. Crowe, F. J., Hall, D. H., Greathead, A. S., and Baghott, K. G. 1980. Inoculum density of Sclerotium cepivorum and the incidence of white rot of onion and garlic. Phytopathology 70:64-69.

5. Ellis, M. B., and Holliday, P. 1972. Alternaria radicina. No 346. CMI Descriptions of Pathogenic Fungi and Bacteria. Commonw. Mycol. Inst., Kew, England.

6. Geng, S., and Hills, F. J. 1989. Biometrics in Agricultural Science. Kendall/Hunt Publishing Co., Dubuque, IA.

7. Grogan, R. G., and Snyder, W. C. 1952. The occurrence and pathological effects of Stemphylium radicinum on carrots in California. Phytopathology 42:215-218.

8. Hall, R. 1996. Inoculum dynamics of Fusarium solani f. sp. phaseoli and management of Fusarium root rot of bean. Pages 279310 in: Principles and Practices of Managing Soilborne Plant Pathogens. R. Hall, ed. APS Press, St. Paul.

9. Hogg, B. M. 1966. Microfungi on leaves of Fagus sylvatica. II. Duration of survival, spore viability and cellulolytic activity. Trans. Br. Mycol. Soc. 49:193-204.

10. Hou, F. C., Campell, C. L., and Beute, M. K. 1982. Inoculum distribution and sampling methods for Cylindrocladium crotalariae in a peanut field. Plant Dis. 66:568-571.

11. Lauritzen, J. I. 1926. The relation of black rot to the storage of carrots. J. Agric. Res. 33:1025-1041.

12. Maude, R. B. 1966. Studies on the etiology of 
black rot, Stemphylium radicinum (Meier, Drechsl., \& Eddy) Neerg., and leaf blight, Alternaria dauci (Kuhn) Groves \& Skolko, on carrot crops; and on fungicide control of their seed-borne infection phases. Ann. Appl. Biol. 57:83-93.

13. Maude, R. B., and Shuring, C. G. 1972. Black rot of carrots. Rep. Natl. Veg. Res. Stn. 20:103.

14. Meier, F. C., Drechsler, C., and Eddy, E. D. 1922. Black rot of carrots caused by Alternaria radicina N. Sp. Phytopathology 12:157-168

15. Mitchell, D. J. 1978. Relationships of inoculum levels of several soilborne species of Phytophthora and Pythium to infection of several hosts. Phytopathology 68:17541759.
16. Murtaza, M., Wahid, A., Ali, S., and Nadeem, A. 1988. Seedling blight of carrots caused by Stemphylium radicinum. Pak. J. Agric. Res. 9:601-603.

17. Neergaard, P. 1948. Danish Species of Alternaria and Stemphylium. Oxford University Press, London.

18. Neergaard, P. 1977. Seed Pathology, Volume I. Halsted Press, New York.

19. Pryor, B. M., Davis, R. M., and Gilbertson, R. L. 1994. Detection and eradication of Alternaria radicina on carrot seed. Plant Dis. 78:452-456.

20. Rotem, J. 1994. The Genus Alternaria: Biology, Epidemiology, and Pathogenicity. American Phytopathological Society, St. Paul.

21. Scott, D. J., and Wenham, H. T. 1972. Occurrence of two seed-borne pathogens, Alter- naria radicina and Alternaria dauci, on imported carrot seed in New Zealand. N.Z. J. Agric. Res. 16:247-250.

22. Sussman, A. S. 1968. Longevity and survivability of fungi. Pages 447-486 in: The Fungi: An Advanced Treatise. Vol. 3. C. C. Ainsworth and A. C. Sussman, eds. Academic Press, New York

23. Tabachnik, J. E., DeVay, R. H., Garber, R. H. and Wakeman, R. J. 1979. Influence of soil inoculum concentrations on host range and disease reactions caused by isolates of Thie laviopsis basicola and comparison of soil assay methods. Phytopathology 69:974-977.

24. Tsuneda, A., and Skoropad, W. P. 1977. Formation of microsclerotia and chlamydospores from conidia of Alternaria brassicae. Can. J. Bot. 56:1333-1334. 